\title{
Factors for Treatment Success in Anisometropic Amblyopia: Effect of Refractive Errors of the Amblyopic Eyes
}

Daye Diana Choi

Kim's Eye Hospital

Dae Hee Kim

Kim's Eye Hospital

Ungsoo Samuel Kim

Kim's Eye Hospital

Seung-Hee Baek ( $\nabla$ drslitlamp@kimeye.com )

Kim's Eye Hospital

\section{Research Article}

Keywords: spherical equivalent, adjusted odds ratio, BCVA in amblyopic eyes, anisometropic amblyopia

Posted Date: June 22nd, 2021

DOl: https://doi.org/10.21203/rs.3.rs-635271/v1

License: @ (1) This work is licensed under a Creative Commons Attribution 4.0 International License. Read Full License 


\section{Abstract}

Purpose: To investigate the factors for treatment success in anisometropic amblyopia according to the spherical equivalent (SE) type of amblyopic eyes.

Methods: Medical records of 397 children with anisometropic amblyopia aged 3 to 12 years during 2010 2016 were retrospectively reviewed. Anisometropia was defined as $\geq 1$ diopter (D) difference in $S E$, or $\geq 1.5 \mathrm{D}$ difference of cylindrical error between the eyes. According to the SE of amblyopic eyes, patients were categorized into hyperopia (SE $\geq 1 \mathrm{D})$, emmetropia $(-1<\mathrm{SE}<+1$ ) and myopia (SE $\leq-1 D)$ groups. Treatment success was defined as achieving interocular LogMAR visual acuity difference $<0.2$. Multivariate logistic regression was used to analyze the factors for treatment success.

Results: Significant factors for the amblyopia treatment success in hyperopia group $(n=270)$ were younger age [adjusted odds ratio $(\mathrm{aOR})(95 \%$ confidence interval, $\mathrm{Cl})=0.60(0.41-0.88)]$, larger astigmatism of sound eye [aOR $(95 \% \mathrm{Cl})=0.04(0-0.78)]$, better $\mathrm{BCVA}$ in amblyopic eyes at presentation [aOR $(95 \% \mathrm{Cl})=0.01(0-0.16)$ ], longer follow-up period [aOR $(95 \% \mathrm{Cl})=1.1(1.04-1.17)]$, and no comorbid strabismus [aOR $(95 \% \mathrm{Cl})=0.25(0.06-0.99)$ ]. In myopia group $(\mathrm{n}=68)$, older age [aOR $(95 \% \mathrm{Cl})=0.45(0.20-0.97)$ ] and worse BCVA in amblyopic eyes [aOR $(95 \% \mathrm{Cl})=0.04(0-0.61)]$ were inversely associated with higher odds of treatment success. There was no significant factor for treatment success in emmetropia group $(n=59)$.

Conclusions: The type of refractive error of amblyopic eyes at presentation affects the factors for treatment success of anisometropic amblyopia.

\section{Introduction}

Anisometropia, the difference in refractive errors between the two eyes, is the most common cause of amblyopia in children when it is large. Amblyopia has prevalence reported as $1-4 \%$ in preschool-aged children, ${ }^{1-4}$ and it may lead to irreversible vision impairment if untreated during young ages. Extensive researches have been conducted to find factors that influence the outcome of amblyopia treatment, mostly in anisometropic and/or strabismic amblyopia, and various and conflicting results have been reported. ${ }^{5-8}$ There are $^{-1}$ also numerous reports of amblyopia treatment methods and their outcome using randomized controlled trials, however, strict compliance to one treatment protocol is not always possible in the real world clinics, therefore the exact treatment method and duration vary considering each patient and guardian at physician's discretion. Even with the diversity in treatment execution, treatment of anisometropic amblyopia is successful in most cases, and there seems to be clinical characteristics of patients that lead to treatment success more easily. Our clinical experience from pediatric ophthalmology clinic in a large eye hospital led to a hypothesis that anisometropic amblyopia treatment prognosis vary depending on refractive error type in amblyopic eyes. Factors associated with the refractive error that may affect the result of anisometropic amblyopia treatment may include the spherical equivalent (SE) of the amblyopic eye, the degree of astigmatism of amblyopic eye, and/or the degree of difference in refractive errors between the two eyes. To our knowledge, there have been a few papers that attempts to analyze the factors that influence the success of amblyopia treatment according to the refractive error type of amblyopic eye.,9-12 In our previous study, we found that treatment success rate was the highest, and the duration to treatment success was shortest in the emmetropia group categorized by SE of amblyopic eyes. ${ }^{13}$. Our clinical impression was that SE type of amblyopic eye affects treatment success more than the SE difference, and hyperopic amblyopes behave differently from myopic amblyopes. In this study, we aimed to ascertain the effect of refractive error of amblyopic eye on the treatment success, and to confirm whether the factors affecting treatment success were different according to refractive error type of amblyopic eye in a usual pediatric ophthalmology practice.

\section{Methods}

This study retrospectively reviewed medical records of patients aged 3 to 12 years who were diagnosed with anisometropic amblyopia at Strabismus \& Pediatric Ophthalmology Center in Kim Eye Hospital between the period of January 1, 2010, and December 31, 2016. The patients who had any other ocular pathology or systemic condition that might affect visual acuity or those who had developmental delay were excluded from this study. Any patient with a follow-up period of less than 6 months was also excluded from this study to rule out the cases without sufficient treatment duration to reach success. Amblyopia was defined as the best corrected visual acuity (BCVA) difference of more than two logarithm of the minimum angle of resolution (logMAR) lines between the two eyes. Anisometropia was defined as spherical equivalent difference of more than 1 diopter $(D)$, or cylinder difference of more than $1.5 \mathrm{D}$ regardless of meridians, between the two eyes. Age at presentation, sex, BCVA at the first visit, refraction of both eyes, ocular alignment and type of manifest 
strabismus, previous amblyopia treatment history, and BCVA at the last visit were collected retrospectively using electronic medical records. Visual acuity was measured using a Snellen chart and converted to LogMAR values for analyses. Amblyopia treatment was started with a full spectacle correction after cycloplegic refraction. Patients were followed usually 1 or 2 months after spectacle prescription, and occlusion with patching was prescribed if there was no vision improvement in amblyopic eye. Occlusion dosage was determined considering the degree of amblyopia and response to treatment, usually from one to six hours per day. Occlusion was continued aiming for equal visual acuity on both eyes, as long as the patient and caregiver cooperate. Subjects were followed up every 2-4 months.

Subjects were categorized according to the SE of amblyopic eye by cycloplegic refraction at the first examination, into the hyperopia group (SE $\geq 1 \mathrm{D})$, emmetropia group $(-1<S E<+1)$, and myopia group (SE $\leq-1 \mathrm{D})$. The treatment success was defined as achieving BCVA difference of less than two logMAR lines between the two eyes. Treatment success during the follow-up was primary outcome for univariate and multivariate logistic regression analysis. All Statistical analysis was performed using R 3.6.0 Statistical Software ( $R$ foundation for statistical computing, Vienna, Austria). To compare the three SE groups, Chi-squared test and Kruskal-Wallis test were performed using R Statistical Software. Post-hoc analysis was conducted using Mann-Whitney test, and p-values $<0.017$ were considered statistically significant according to the Bonferroni's adjustment. Univariate and Multiple logistic regression analyses were performed to determine the influence of each factor on the success of amblyopia treatment. Factors which was statistically significant in univariate logistic regression analysis were included in multivariate logistic regression. Factors of interest (SE of amblyopic eye, cylinder of amblyopic eye, cylinder of sound eye, and SE difference between amblyopic and sound eyes at presentation) were also included in multivariate logistic regression analysis regardless of their significance in univariate analysis. Significant multicollinearity was encountered between the cylinder of the amblyopic eye and the difference of cylinder between the amblyopic eye and sound eye (Pearson's correlation coefficient $-0.887, p=0.001$, data not shown), and we analyzed each factor separately. However, putting only one variable out of them did not change significant factors in multivariate analysis results in all of the SE groups, and this paper presents results that included sound eye cylinder values. Age at the last visit were calculated in univariate analyses, but excluded for multivariable analyses due to multicollinearity with age at first exam. All of the refractive errors used in this study were determined in minus cylinder form, thus an increase of cylinder value means decrease of absolute value of cylinder. This study was performed in accordance with the tenets of the Declaration of Helsinki. Approval to conduct this study was obtained from the Institutional Review Board of Kim's Eye Hospital (IRB 2018-01-012). Informed consent was waived by the Institutional Review Board because this study was conducted retrospectively using medical records without identifiable private information.

\section{Results}

A total of 397 children (193 male and 205 female) were included in this study. According to the SE of amblyopic eye at the first exam, there were 270 subjects (68.01\%) in the hyperopia group, 59 subjects (14.61\%) in the emmetropia group, and 68 subjects (17.13\%) in the myopia group. Overall, as for the treatment of amblyopia, both glasses and patching were used in 365 (94.81\%), prescribing glasses only in 20 (5.19\%), and glasses and atropine penalization in 12 (3.12\%) patients. Mean follow-up duration was 33.4 months (Standard deviation, $S D=18.7)$. Detailed demographics and clinical characteristics of the study population are shown in Table 1. Age at presentation, follow-up duration, comorbid strabismus, and previous amblyopia treatment history were not significantly different among the SE groups. The emmetropia group had the smallest interocular BCVA difference and SE difference, and the largest interocular cylinder difference between the two eyes at presentation among the three SE groups. Treatment success rate during the follow-up was significantly different among the SE groups (96.61\% in emmetropia group, $91.48 \%$ in hyperopia, and $82.35 \%$ in myopia group, respectively, $p=0.016$ by Chi-square test, Table 1 ). BCVA of the amblyopic eyes were not significantly different among the SE groups when they achieved the treatment success $(p=0.343)$. 
Table 1

Clinical characteristics of anisometropic amblyopia patients in hyperopic, emmetropic, and myopic amblyopia groups

\begin{tabular}{|c|c|c|c|c|c|}
\hline & $\begin{array}{l}\text { Hyperopia group } \\
\text { (1) }\end{array}$ & $\begin{array}{l}\text { Emmetropia group } \\
\text { (2) }\end{array}$ & $\begin{array}{l}\text { Myopia } \\
\text { group } \\
\text { (3) }\end{array}$ & $\begin{array}{l}\text { p- } \\
\text { values* }\end{array}$ & $\begin{array}{l}\text { Post-hoc } \\
\text { test }\end{array}$ \\
\hline Number of patients & 270 & 59 & 68 & & \\
\hline Age at presentation & $5.4 \pm 1.7$ & $5.2 \pm 1.4$ & $5.0 \pm 1.1$ & $0.622^{a}$ & \\
\hline Number of male subjects (n, \%) & $140(51.85)$ & $30(50.85)$ & $\begin{array}{l}23 \\
(33.82)\end{array}$ & 0.07 & \\
\hline Strabismus (n, \%) & 55 (20.37) & $32(54.24)$ & $1(1.5)$ & $0.066^{b}$ & \\
\hline Esotropia & $51(18.89)$ & $17(28.81)$ & 0 & & \\
\hline Exotropia & $3(1.11)$ & $4(6.78)$ & 0 & & \\
\hline Vertical strabismus & $1(0.37)$ & $11(18.64)$ & $1(1.47)$ & & \\
\hline None & $215(79.62)$ & $27(45.76)$ & $\begin{array}{l}67 \\
(98.53)\end{array}$ & & \\
\hline $\begin{array}{l}\text { Previous amblyopia treatment history } \\
\text { Yes }(n, \%)\end{array}$ & $39(14.44 \%)$ & $7(11.86 \%)$ & $\begin{array}{l}9 \\
(13.24 \%)\end{array}$ & $0.862^{b}$ & \\
\hline \multicolumn{6}{|l|}{ Amblyopic eye at presentation } \\
\hline SE (D) & $4.5 \pm 1.6$ & $0.1 \pm 0.5$ & $-5.0 \pm 3.4$ & $0.001^{a}$ & $1>2>3^{c}$ \\
\hline Sph (D) & $5.0 \pm 1.5$ & $1.6 \pm 0.7$ & $-4.0 \pm 3.3$ & $0.001^{a}$ & $1>2>3^{c}$ \\
\hline Cyl (D) & $-1.1 \pm 1.1$ & $-3.2 \pm 1.0$ & $-1.9 \pm 1.2$ & $0.001^{a}$ & $1>3>2^{c}$ \\
\hline BCVA (logMAR) & $0.6 \pm 0.2$ & $0.4 \pm 0.1$ & $0.6 \pm 0.4$ & $\begin{array}{l}< \\
0.001^{a}\end{array}$ & $1=3>2^{c}$ \\
\hline \multicolumn{6}{|l|}{ Sound eye at presentation } \\
\hline SE (D) & $1.9 \pm 1.4$ & $0.7 \pm 0.6$ & $-0.3 \pm 2.1$ & $\begin{array}{l}< \\
0.001^{a}\end{array}$ & $1>2>3^{c}$ \\
\hline Sph (D) & $2.1 \pm 1.5$ & $1.1 \pm 0.8$ & $0.1 \pm 2.0$ & $0.001^{a}$ & $1>2>3^{c}$ \\
\hline Cyl (D) & $-0.4 \pm 1.5$ & $-0.8 \pm 0.8$ & $-0.9 \pm 2.0$ & $0.001^{a}$ & $1>2=3^{c}$ \\
\hline BCVA (logMAR) & $0.1 \pm 0.1$ & $0.1 \pm 0.1$ & $0.1 \pm 0.1$ & $0.227^{a}$ & \\
\hline
\end{tabular}

SD, standard deviation; SE, spherical equivalent; Sph, sphere component; Cyl, cylinder component; BCVA, best-corrected visual acuity; $\triangle B C V A$, difference of BCVA between the two eyes; $\triangle S E$ = difference of SE between the two eyes; $\Delta$ Cyl = difference of cylinder between the two eyes

Cylindrical error was described as negative values. Numeric values are expressed as mean $\pm \mathrm{SD}$, and categorical variables are expressed as number (\%).

p-values* compare hyperopia, emmetropia, and myopia groups, and p-values $<0.05$ are displayed in bold.

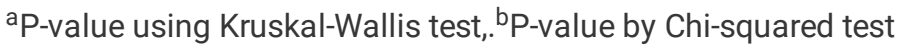

'Post-hoc analysis was conducted using the Mann-Whitney test, and p-values $<0.017$ were considered statistically significant according to the Bonferroni's adjustment. 


\begin{tabular}{|c|c|c|c|c|c|}
\hline & $\begin{array}{l}\text { Hyperopia group } \\
\text { (1) }\end{array}$ & $\begin{array}{l}\text { Emmetropia group } \\
(2)\end{array}$ & $\begin{array}{l}\text { Myopia } \\
\text { group } \\
(3)\end{array}$ & $\begin{array}{l}\text { p- } \\
\text { values* }\end{array}$ & $\begin{array}{l}\text { Post-hoc } \\
\text { test }\end{array}$ \\
\hline$\triangle \mathrm{BCVA}$ at presentation & $0.5 \pm 0.2$ & $0.3 \pm 0.1$ & $0.6 \pm 0.4$ & $<.001^{\mathrm{a}}$ & $1=3>2^{c}$ \\
\hline$\Delta S E$ at presentation (D) & $2.6 \pm 1.4$ & $0.7 \pm 0.5$ & $4.6 \pm 2.9$ & $\begin{array}{l}<.001^{\mathrm{a}} \\
0.00\end{array}$ & $3>1>2^{c}$ \\
\hline$\Delta$ Cyl at presentation (D) & $0.8 \pm 0.9$ & $2.4 \pm 1.0$ & $1.1 \pm 0.9$ & $\begin{array}{l}<.001^{\mathrm{a}} \\
0.000\end{array}$ & $2>3>1^{c}$ \\
\hline Treatment success during the follow-up $(n, \%)$ & $247(91.48)$ & $57(96.61)$ & $\begin{array}{l}56 \\
(82.35)\end{array}$ & $0.016^{b}$ & \\
\hline Duration to treatment success (months) & $6.0 \pm 7.1$ & $4.1 \pm 4.8$ & $6.6 \pm 7.3$ & $0.012^{\mathrm{a}}$ & $1=3>2^{c}$ \\
\hline $\begin{array}{l}\text { BCVA of amblyopic eye at treatment success } \\
\text { (logMAR) }\end{array}$ & $0.157 \pm 0.07$ & $0.16 \pm 0.07$ & $\begin{array}{l}0.20 \pm \\
0.09\end{array}$ & $0.343^{\mathrm{a}}$ & \\
\hline Follow-up duration (months) & $34.3 \pm 18.5$ & $32.6 \pm 19.1$ & $\begin{array}{l}30.4 \pm \\
19.0\end{array}$ & $0.149^{\mathrm{a}}$ & \\
\hline \multicolumn{6}{|c|}{$\begin{array}{l}\text { SD, standard deviation; } S E \text {, spherical equivalent; Sph, sphere component; Cyl, cylinder component; BCVA, best-corrected visual acuity; } \\
\triangle B C V A \text {, difference of BCVA between the two eyes; } \triangle S E \text { = difference of SE between the two eyes; } \Delta \text { Cyl = difference of cylinder between } \\
\text { the two eyes }\end{array}$} \\
\hline \multicolumn{6}{|c|}{$\begin{array}{l}\text { Cylindrical error was described as negative values. Numeric values are expressed as mean } \pm \text { SD, and categorical variables are } \\
\text { expressed as number (\%). }\end{array}$} \\
\hline \multicolumn{6}{|c|}{ p-values* compare hyperopia, emmetropia, and myopia groups, and p-values $<0.05$ are displayed in bold. } \\
\hline \multicolumn{6}{|c|}{${ }^{\mathrm{a} P}$-value using Kruskal-Wallis test,. ${ }^{\mathrm{b}} \mathrm{P}$-value by Chi-squared test } \\
\hline
\end{tabular}

\section{Hyperopia group}

In the univariate analysis of the hyperopia group, SE of the sound eye at the first exam, BCVA of the sound eye, and follow-up duration significantly increased the odds of treatment success, whereas age at presentation, SE of the amblyopic eye at the first exam, cylinder of the sound eye at the first exam, SE difference at the first exam, BCVA of the amblyopic eye at the first exam, BCVA difference at the first exam, and concomitant strabismus significantly decreased the odds of treatment success (Table 2). 
Table 2

Crude odds ratio values of factors influencing amblyopia treatment success during follow-up in hyperopia, emmetropia, and myopia groups

\begin{tabular}{|c|c|c|c|c|c|c|c|}
\hline & & \multicolumn{2}{|c|}{ Hyperopia group $(n=270)$} & \multicolumn{2}{|l|}{ Emmetropia group $(n=59)$} & \multicolumn{2}{|c|}{ Myopia group $(n=68)$} \\
\hline & & crude OR $(95 \% \mathrm{Cl})$ & $\begin{array}{l}P \\
\text { value }\end{array}$ & crude OR $(95 \% \mathrm{Cl})$ & $\begin{array}{l}P \\
\text { value }\end{array}$ & $\begin{array}{l}\text { crude OR } \\
(95 \% \mathrm{Cl})\end{array}$ & $\begin{array}{l}P \\
\text { value }\end{array}$ \\
\hline $\begin{array}{l}\text { Age at } \\
\text { presentation } \\
\text { (years) }\end{array}$ & & $0.702(0.574,0.857)$ & $\hat{0} .001$ & $0.114(0.006,2.373)$ & 0.1611 & $\begin{array}{l}0.526 \\
(0.299,0.926)\end{array}$ & 0.0261 \\
\hline $\begin{array}{l}\text { Sex: Female } \\
\text { vs. male }\end{array}$ & & $0.839(0.356,1.972)$ & 0.6865 & $0.966(0.058,16.2)$ & 0.9805 & $\begin{array}{l}1.508 \\
(0.42,5.409)\end{array}$ & 0.5285 \\
\hline \multirow[t]{2}{*}{$\begin{array}{l}\text { SE at first } \\
\text { exam (D) }\end{array}$} & $\begin{array}{l}\text { Amblyopic } \\
\text { eye }\end{array}$ & $0.675(0.514,0.885)$ & 0.0045 & $0.08(0.001,5.008)$ & 0.2315 & $\begin{array}{l}1.189 \\
(1.002,1.411)\end{array}$ & 0.047 \\
\hline & Sound eye & $1.549(1.04,2.308)$ & 0.0315 & $89.965(1.604,5046)$ & 0.0285 & $\begin{array}{l}0.847 \\
(0.489,1.469)\end{array}$ & 0.5553 \\
\hline \multirow[t]{2}{*}{$\begin{array}{l}\text { Cylinder at first } \\
\text { exam (D) }\end{array}$} & $\begin{array}{l}\text { Amblyopic } \\
\text { eye }\end{array}$ & $0.855(0.557,1.311)$ & 0.4728 & $0.272(0.078,0.949)$ & 0.0411 & $\begin{array}{l}0.642 \\
(0.349,1.18)\end{array}$ & 0.1536 \\
\hline & Sound eye & $0.039(0.005,0.317)$ & 0.0024 & $0.288(0.011,7.576)$ & 0.4554 & $\begin{array}{l}0.593 \\
(0.248,1.422)\end{array}$ & 0.2419 \\
\hline $\begin{array}{l}\triangle S E \text { at first } \\
\text { exam (D) }\end{array}$ & & $0.45(0.325,0.625)$ & $\hat{0} .001$ & $0.587(0.065,5.284)$ & 0.6346 & $\begin{array}{l}0.752 \\
(0.609,0.928)\end{array}$ & 0.0079 \\
\hline $\begin{array}{l}\Delta \text { cylinder at } \\
\text { first exam (D) }\end{array}$ & & $0.914(0.594,1.406)$ & 0.6823 & $3.125(0.546,17.877)$ & 0.2003 & $\begin{array}{l}1.126 \\
(0.534,2.375)\end{array}$ & 0.7545 \\
\hline \multirow{2}{*}{$\begin{array}{l}\text { BCVA at first } \\
\text { exam } \\
(\log M A R)\end{array}$} & Amblyopic & $0.017(0.003,0.097)$ & $\hat{0} .001$ & $0.027(0,17.732)$ & 0.2761 & $\begin{array}{l}0.054 \\
(0.008,0.367)\end{array}$ & 0.0028 \\
\hline & Sound & $\begin{array}{l}5560.108 \\
(1.812,17059513.232)\end{array}$ & 0.0353 & $\begin{array}{l}562.179 \\
(0,1357708246281482)\end{array}$ & 0.6634 & $\begin{array}{l}101.99 \\
(0.047,223393)\end{array}$ & 0.2386 \\
\hline $\begin{array}{l}\text { Follow-up } \\
\text { duration } \\
\text { (months) }\end{array}$ & & $1.069(1.028,1.111)$ & $\hat{0} 001$ & $0.951(0.89,1.016)$ & 0.135 & $\begin{array}{l}1.014 \\
(0.978,1.051)\end{array}$ & 0.456 \\
\hline $\begin{array}{l}\text { Age at the last } \\
\text { FU (years) }\end{array}$ & & $0.962(0.797,1.161)$ & 0.6851 & $0.462(0.234,0.912)$ & 0.026 & $\begin{array}{l}0.872 \\
(0.624,1.22)\end{array}$ & 0.4254 \\
\hline $\begin{array}{l}\text { Amblyopia } \\
\text { Type: } \\
\text { (Ref = pure } \\
\text { anisometropic) }\end{array}$ & $\begin{array}{l}\text { Concurrent } \\
\text { manifest } \\
\text { strabismus }\end{array}$ & $0.399(0.166,0.957)$ & 0.0396 & $0.118(0.006,2.134)$ & 0.1478 & $\begin{array}{l}1.222 \\
(0.234,6.397)\end{array}$ & 0.8122 \\
\hline \multirow{2}{*}{$\begin{array}{l}\text { Treatment } \\
\text { Modality: } \\
\text { (ref.=None) }\end{array}$} & $\begin{array}{l}\text { Glasses } \\
\text { only }\end{array}$ & $2.413(0.489,11.903)$ & 0.2794 & $0(0, \operatorname{lnf})$ & 0.9963 & $\begin{array}{l}1.136 \\
(0.115,11.182)\end{array}$ & 0.9127 \\
\hline & $\begin{array}{l}\text { Glasses + } \\
\text { Patching }\end{array}$ & $9454402.746(0$, Inf $)$ & 0.9898 & & & $\begin{array}{l}3912840.198 \\
(0, \operatorname{lnf})\end{array}$ & 0.9929 \\
\hline \multirow{2}{*}{$\begin{array}{l}\text { Glasses } \\
\text { Compliance: } \\
\text { (ref.=Poor) }\end{array}$} & Fair & $0.786(0.075,8.222)$ & 0.8405 & $284845148.108(0, \operatorname{lnf})$ & 0.9975 & $0(0, \operatorname{lnf})$ & 0.9927 \\
\hline & Good & $0.714(0.088,5.792)$ & 0.7527 & $12(0.59,243.867)$ & 0.1058 & $0(0, \operatorname{lnf})$ & 0.993 \\
\hline $\begin{array}{l}\text { Previous } \\
\text { amblyopia }\end{array}$ & $\begin{array}{l}\text { Glasses } \\
\text { only }\end{array}$ & $0.45(0.12,1.7)$ & 0.24 & $0.1(0.01,1.82)$ & 0.119 & $\begin{array}{l}9749852.828 \\
(0, \operatorname{lnf})\end{array}$ & 0.9944 \\
\hline
\end{tabular}

$=$ None)

* $P$-value $<0.05$ is considered statistically significant and displayed in bold.

$\mathrm{OR}=$ odds ratio; $\mathrm{Cl}$ = confidence interval; $\mathrm{D}$ = Diopter; $\mathrm{SE}$ = spherical equivalent; $\mathrm{BCVA}$ = best-corrected visual acuity; FU = follow-up; inf = infinity; ref.= reference level; $\Delta \mathrm{SE}=$ difference of $\mathrm{SE}$ between two eyes; $\Delta \mathrm{Cyl}=$ difference of cylinder between two eyes

Cylindrical error was described as negative values. Numeric values are expressed as mean \pm SD, and categorical variables are expressed as number (\%). 


\begin{tabular}{|c|c|c|c|c|c|c|}
\hline \multirow[b]{2}{*}{$\begin{array}{l}\text { Glasses + } \\
\text { Patching }\end{array}$} & \multicolumn{2}{|c|}{ Hyperopia group $(n=270)$} & \multicolumn{2}{|c|}{ Emmetropia group $(n=59)$} & \multicolumn{2}{|c|}{ Myopia group $(n=68)$} \\
\hline & $0.09(0.03,0.28)$ & $<.001$ & $834212(0, \operatorname{lnf})$ & 0.997 & $\begin{array}{l}1.146 \\
(0.121,10.815)\end{array}$ & 0.9054 \\
\hline
\end{tabular}

* $P$-value $<0.05$ is considered statistically significant and displayed in bold.

$\mathrm{OR}$ = odds ratio; $\mathrm{Cl}$ = confidence interval; $\mathrm{D}=$ Diopter; $\mathrm{SE}=$ spherical equivalent; $\mathrm{BCVA}$ = best-corrected visual acuity; FU = follow-up; inf = infinity; ref.= reference level; $\Delta \mathrm{SE}$ = difference of $\mathrm{SE}$ between two eyes; $\Delta C y \mathrm{l}=$ difference of cylinder between two eyes

Cylindrical error was described as negative values. Numeric values are expressed as mean \pm SD, and categorical variables are expressed as number (\%).

In the multivariate analysis, follow-up duration [adusted OR, aOR (95\% confidence interval, $\mathrm{Cl})=1.1(1.04,1.17)$ ] significantly increased the odds of treatment success. On the contrary, age at presentation [aOR $(95 \% \mathrm{Cl})=0.6(0.41-0.88)$ ], larger negative cylinder of the first exam in sound eye [aOR $(95 \% \mathrm{Cl})=0.04(0-0.78)$ ], larger LogMAR BCVA of amblyopic eye at the first exam [aOR $(95 \% \mathrm{Cl})=0.01(0-0.16)$ ], and concomitant strabismus [aOR $(95 \% \mathrm{Cl})=0.25(0.06,0.99)$ ] significantly decreased the odds of treatment success (Table 3$)$. SE of the amblyopic eye and the sound eye at the first exam, a cylinder of amblyopic eye at the first exam, SE difference at presentation, and BCVA of the sound eye at presentation were not significant factors in multivariate analysis of the hyperopia group. 
Table 3

Adjusted odds ratio values of factors influencing amblyopia treatment success during follow-up in hyperopia, emmetropia, and myopia groups

\begin{tabular}{|c|c|c|c|c|c|c|c|}
\hline & & \multicolumn{2}{|c|}{$\begin{array}{l}\text { Hyperopia group }(n= \\
270)^{a}\end{array}$} & \multicolumn{2}{|c|}{$\begin{array}{l}\text { Emmetropia group }(n= \\
59)^{b}\end{array}$} & \multicolumn{2}{|c|}{ Myopia group $(n=68)^{c}$} \\
\hline & & $\begin{array}{l}\text { adj. OR } \\
(95 \% \mathrm{Cl})\end{array}$ & $\begin{array}{l}\text { adj. } P \\
\text { value }\end{array}$ & $\begin{array}{l}\text { adj. OR } \\
(95 \% \mathrm{Cl})\end{array}$ & $\begin{array}{l}\text { adj. } P \\
\text { value }\end{array}$ & $\begin{array}{l}\text { adj. OR } \\
(95 \% \mathrm{Cl})\end{array}$ & $\begin{array}{l}\text { adj. } P \\
\text { value }\end{array}$ \\
\hline Age at presentation (years) & & $\begin{array}{l}0.6 \\
(0.41,0.88)\end{array}$ & 0.009 & $0(0, \operatorname{lnf})$ & 0.998 & $\begin{array}{l}0.45 \\
(0.2,0.97)\end{array}$ & 0.041 \\
\hline \multirow[t]{2}{*}{ SE at first exam (D) } & $\begin{array}{l}\text { Amblyopic } \\
\text { eye }\end{array}$ & $1.3(0.63,2.7)$ & 0.475 & $0(0, \operatorname{lnf})$ & 0.996 & $\begin{array}{l}0.98 \\
(0.55,1.73)\end{array}$ & 0.934 \\
\hline & Sound eye & & & $6.13(0, \operatorname{lnf})$ & 0.996 & & \\
\hline \multirow[t]{2}{*}{ Cylinder at first exam (D) } & $\begin{array}{l}\text { Amblyopic } \\
\text { eye }\end{array}$ & $\begin{array}{l}1.12 \\
(0.51,2.5)\end{array}$ & 0.773 & $0(0, \operatorname{lnf})$ & 0.996 & & \\
\hline & Sound eye & $0.04(0,0.78)$ & 0.033 & & & & \\
\hline$\Delta S E$ at first exam (D) & & $\begin{array}{l}0.53 \\
(0.26,1.08)\end{array}$ & 0.08 & & & $\begin{array}{l}0.96 \\
(0.52,1.8)\end{array}$ & 0.909 \\
\hline \multirow[t]{2}{*}{ BCVA at first exam (logMAR) } & $\begin{array}{l}\text { Amblyopic } \\
\text { eye }\end{array}$ & $0.01(0,0.16)$ & 0.001 & & & $\begin{array}{l}0.04 \\
(0,0.61)\end{array}$ & 0.021 \\
\hline & Sound eye & $\begin{array}{l}0.26 \\
(0,11446.13)\end{array}$ & 0.804 & & & & \\
\hline Follow-up duration (months) & & $\begin{array}{l}1.1 \\
(1.04,1.17)\end{array}$ & $<0.001$ & & & & \\
\hline $\begin{array}{l}\text { Presence of manifest strabismus: } \\
\text { Yes vs. no }\end{array}$ & & $\begin{array}{l}0.25 \\
(0.06,0.99)\end{array}$ & 0.049 & & & & \\
\hline
\end{tabular}

$P$-value less than 0.05 is considered significant and displayed in bold.

Adj.= adjusted; $\mathrm{OR}=$ odds ratio; $\mathrm{Cl}$ = confidence interval; $\mathrm{D}=$ diopter; $\mathrm{SE}$ = spherical equivalent; BCVA = best-corrected visual acuity; FU = follow-up; $\triangle S E$ = difference of $S E$ between two eyes; $\triangle$ Cyl = difference of cylinder between two eyes; Inf = Infinity

Cylindrical error was described in negative values.

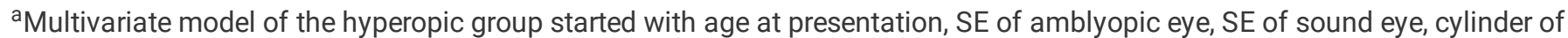
amblyopic eye, cylinder of sound eye, SE difference between two eyes, logMAR BCVA of amblyopic eye, logMAR BCVA of sound eye at first exam, follow-up duration, and presence of manifest strabismus.

${ }^{b}$ Multivariate model of the emmetropia group started with age at presentation, SE of amblyopic eye, SE of sound eye, cylinder of amblyopic eye, cylinder of sound eye, cylinder and SE difference between the two eyes at first exam.

cMultivariate model of the myopic group started with age at presentation, SE of amblyopic eye, cylinder of sound eye, SE difference between two eyes, and logMAR BCVA of the amblyopic eye on the first exam.

\section{Emmetropia group}

In the univariate analysis of the emmetropia group, larger SE of the sound eye at the first exam [crude $0 \mathrm{R}(95 \% \mathrm{Cl})=89.97(1.604$, 5046.42)] significantly increased the odds of treatment success, but larger negative cylinder of the amblyopic eye at the first exam [crude OR $(95 \% \mathrm{Cl})=0.272(0.078,0.949)$ ] significantly decreased the odds of treatment success (Table 2$)$. However, both were not significant factors in multivariate analysis in this group (Table 3 ).

\section{Myopia group}

Univariate analysis of the myopia group found that the SE of amblyopic eye at the first exam significantly increased the odds of treatment success, whereas age at presentation, SE difference at the first exam, and BCVA of the amblyopic eye at the first exam decreased the odds of treatment success (Table 2). However, SE of the amblyopic eye at the first exam and SE difference at the first exam were not significant factors when considering other factors in multivariate analysis. On multivariate analysis, only older age at presentation [aOR $(95 \% \mathrm{Cl})=0.45(0.2,0.97)$ ] and higher logMAR BCVA of amblyopic eye at the first exam [aOR $(95 \% \mathrm{Cl})=0.04(0,0.61)$ ] significantly decreased the odds of treatment success in the myopia group (Table 3 ). 


\section{Discussions}

In the present study, 397 patients who were treated > 6 months for anisometropic amblyopia in a secondary referral eye hospital were analyzed. The factors affecting treatment success in anisometropic amblyopia were different according to the SE type of the amblyopic eyes. The age and the BCVA of the amblyopic eye at presentation were factors affecting the odds of amblyopia treatment success in hyperopia and myopia groups. Smaller astigmatism of sound eye at presentation, longer follow-up period, and the absence of comorbid strabismus were significant factors increasing the odds of treatment success only in hyperopia group. Furthermore, there was no significant factor affecting treatment success in the emmetropia group.

There are diverse reports about treatment outcome of anisometropic amblyopia. However, as the hyperopic difference in refractive error are more amblyogenic than myopic differences ${ }^{14}$, many anisometropic amblyopia studies were comprised of mostly hyperopic patients ${ }^{6,15,16}$. Small number of papers have analyzed treatment outcome according to refractive type of amblyopic eye. Keech et.al. reported that the refractive type of anisometropia was significant factor affecting anisometropic amblyopia treatment outcome as patients with myopic and compound myopic/mixed astigmatism had poorer visual outcomes than hyperopia ${ }^{7}$. On the contrary, Meenakshi et al. found that greatest amount of improvement in visual acuity was seen in myopic anisometropic patients and the least in hyperopes ${ }^{5}$. Husseint et al. reported that the refractive type of amblyopia was not a significant factor for amblyopia treatment outcome $^{15}$. Our study classified anisometropic amblyopia as hyperopia, emmetropia, and myopia groups according to SE of amblyopic eye at first exam and analyzed the factors for treatment success.

Treatment success rates during the follow-up were significantly different according to SE type in amblyopic eye at the first exam; the highest success rate in emmetropia group, followed by hyperopia group and then myopia group. This result is in accordance to our previous study, ${ }^{13}$ even though this study included only the patients with sufficient follow-up duration of more than six months, considering the duration for treatment success in our previous study (mean 6.0, 4.1, and 6.6 months for the hyperopia, emmetropia, and myopia group). The emmetropia group had the shortest duration to treatment success, and highest treatment success rate. The hyperopia group had higher treatment success rate during the follow-up than myopia group.

These different treatment results according to SE type in amblyopic eye group made us questioned which of the refractive error factors, including the amount of SE or cylinder of the amblyopic eye, or SE or cylinder difference between the two eyes, are more important for treatment success in anisometropic amblyopia, and if there are differences in treatment success factors by the SE groups. In our univariate analyses results, the significance of SE in amblyopic eye, cylinder of the amblyopic eye, and SE difference were different in each SE group. In univariate analyses of hyperopia group, SE of amblyopic eye, SE of sound eye, cylinder of sound eye, and difference of SE between two eyes at first exam were significant factors. In the univariate analyses of emmetropia group, SE of sound eye and cylinder of amblyopic eye, while in the myopia group, SE of amblyopic eye and difference of SE between two eyes were significant factors. However, the significance disappeared as the other factors were adjusted in each SE group, which implies that SE type was more important than other refractive error-related variables and other factors unrelated to refractive error were more important for treatment success than the refractive error itself within each SE group.

Previously, Hussein et al. reviewed the record of 104 children aged 3 to 8 years with anisometropic amblyopia, and found that neither the type or amount of refractive error nor the difference in the refractive power between the two eyes was a significant risk factor for treatment failure ${ }^{15}$. Myopic anisometropia were only $22 \%$ in their study population, and rest were classified as hyperopic anisometropia. They reported age above 6 at the onset of treatment, and worse than 20/200 initial BCVA of amblyopic eye as failure risk factors. These results are in accordance with our negative results about refractive factors, also with the age and BCVA of amblyopic eye at presentation as significant factors for treatment success in hyperopia and myopia groups. On the contrary, Cobb et al. reviewed 112 children with anisometropic amblyopia who treated with spectacles and patching, and reported that the age at presentation had no effect on the final visual outcome, while the amount of refractive error and degree of anisometropia do correlate strongly with final visual acuity ${ }^{16}$. It is notable that most $(87 \%)$ of their study population were hyperopic and the myopic anisometropia were only $12.5 \%$. Kirandi et al. reviewed 64 children aged 7-9 years with anisometropic amblyopia who were treated with spectacles and patching, and reported that refractive error of SE >+3D in the amblyopic eye was a risk factor for treatment failure ${ }^{6}$. The study population of Kirandi et al. was also mostly comprised of hyperopic anisometropic subjects $(n=60,93.7 \%)$. The results of Cobb et al. and Kirandi et al. may be comparable to our results of hyperopia group. In our hyperopia group, however, the age at presentation was a significant factor, and neither the amount of SE nor the difference of SE were a significant factor for treatment success. These different results may be due to different definition of treatment outcome, and method of analyses. Our study has its merits to analyze the effect of SE amount or the SE difference on the amblyopia treatment success in the hyperopia group, and adjusted factors other than refractive errors, such as follow-up duration or 
concomitant strabismus. Pang et al. prospectively analyzed myopic anisometropic amblyopia patients, and found that the final VA in the amblyopic eye was associated with the VA in the amblyopic eye at baseline and the amount of anisometropia ${ }^{10}$. The improvement in VA with patching was inversely associated with patients age. In the similar manner, the age at presentation and the VA of amblyopic eye at first exam were significant factor for treatment success in our myopia group. However, the difference of SE was not a significant factor in our study.

Despite different treatment success rate according to SE type of amblyopic eye in our study, the SE amount of amblyopic eye at first exam was not a significant factor in all of the SE groups after adjusting potential confounding variables. Similarly, the difference of SE between the two eyes was not significant factor in all SE groups in the multivariate analysis, neither. Although the amount of SE difference is a well-known risk factor for developing amblyopia ${ }^{17}$, our results showed that after adequate optical correction and amblyopia treatment, it is not a significant factor for treatment success in each SE group. Usually we prescribed glasses after cycloplegic refraction at initial visit, and waited for 1 to 2 months to see the effect of optical adaptation. If there was no sign of vision improving, patching or atropine penalization was initiated. Twenty subjects $(5.19 \%)$ achieved treatment success without patching or atropine penalization.

The cylinder value of the amblyopic eye was also not a significant factor for all SE groups in multivariate analyses. The emmetropia group had a larger cylinder value than those of the hyperopia and myopia group. The emmetropia group subjects in this study may have been classified as astigmatic or mixed astigmatic amblyopia in other studies. Our emmetropia group showed higher treatment success compared to the myopia group, and comparably similar to the hyperopia group. This may imply that SE is more important than the cylindrical amount itself, in other words, even if the astigmatism is large, treatment outcome may be good, as long as the SE is close to emmetropia. There are conflicting studies on the impact of astigmatism for the treatment success in amblyopia. Hussein et al. reported that eyes with significant astigmatism were less likely to achieve successful outcomes in cases of anisometropic amblyopia ${ }^{18}$, while others reported that the degree of astigmatism is not a significant factor for treatment outcome ${ }^{6,19}$.

It is interesting that the odds of treatment success in the hyperopia group were associated with the cylinder value of the sound eye. There was a moderate correlation between the cylinder of sound and amblyopic eyes in all SE group (Pearson's correlation coefficient $0.555, p=0.001$, data not shown). However, the cylinder value in the amblyopic eye was not a significant factor for treatment success in any of the three SE groups. We speculated that the larger cylinder value of sound eye would make the cylinder difference between two eyes smaller, however, there was only weak correlation between cylinder value of amblyopic and sound eye (Pearson's correlation coefficient $-0.163, p=0.001$, data not shown). In the multivariate analysis including the cylinder difference between two eyes instead of the cylinder in the amblyopic eye considering multicollinearity, the cylinder difference was not a significant factor for treatment success in any SE group as well. Further studies are needed to interpret these results.

Age at presentation was a significant factor for amblyopia treatment success in hyperopia and myopia group of our study. The younger at presentation, the more likely it was to have the greater odds of treatment success in anisometropic amblyopia. This result agrees with many previous reports, which have found the better visual outcomes in younger than older patients $9,15,20,21$. However, some authors insisted that the age at presentation had no effect on the final visual outcome. ${ }^{7,16,22}$ These various results might be due to the different definition of treatment success. It is notable that the age at presentation was not a significant factor for treatment success in our emmetropia group. One study about astigmatic amblyopia reported that the age at presentation did not influence final visual acuity ${ }^{19}$. Even though our emmetropia group may comparable with usual astigmatic anisometropia group from other study due to its large cylinder value, but our emmetropia group only included subjects who had SE is close to emmetropia. We may speculate that emmetropic $\mathrm{SE}$ is a strong prognostic factor that can overcome the age.

BCVA of amblyopic eye at the first visit was also a significant factor in both the hyperopia and myopia groups. This study showed that the chance of achieving treatment success in both groups depended on the visual acuity of the amblyopic eye at the first visit. These results are consistent with those of previous studies. ${ }^{7,18-20}$ On the contrary, in the emmetropia group, BCVA of the amblyopic eye was not a significant factor affecting treatment success. This result might be due to the fact the initial BCVA of amblyopic eye in emmetropia group was better than the other two SE groups.

Follow-up duration had a significant positive effect on treatment success in the hyperopia group only. The longer follow-up duration made the odds of treatment success increase by 1.1 times. It can be suspected that the longer follow-up duration is associated with good compliance and selection bias, therefore yield good treatment results. However, follow-up duration is not a significant factor for the 
emmetropia and myopia groups whereas their follow-up durations were not significantly different, therefore different SE group demonstrated different treatment response by follow-up duration.

Strabismus was a significant poor prognostic factor for treatment success only in the hyperopia group. The hyperopia group subjects with strabismus had odds of treatment success decreased by 0.25 times than the hyperopia group subjects without strabismus. In myopia group only one subject had vertical strabismus (1.47\%). Fifty-four percent of emmetropia group had strabismus, but strabismus was not a significant factor for treatment success. There were contradictory reports about the effect of strabismus on amblyopia treatment results. Some reported strabismus is not a significant risk factor ${ }^{7,8,18}$, while others found it as a significant failure factor ${ }^{16,23}$. Further study with larger number of subjects is warranted to clarify the influence of strabismus on each refractive type of anisometropic amblyopia treatment result.

The results that there were no significant factors related to treatment success in the emmetropia group might need some interpretation. We speculated that the relatively small number of patients with very high success rates made lack of diversity to predict success and failure in this group.

We focused on achieving treatment success any time during the follow-up, not the success at the last visit in our study. Defining treatment success at the last visit will reflect fluctuation of visual acuity such as recurrence with or without recovery after recurrence. In our study, treatment success rates at the last follow-up were also significantly different among the SE groups ( $96.61 \%$ for emmetropia, $86.30 \%$ for hyperopia, and $77.94 \%$ for myopia group, respectively, $p=0.001$ by Chi-square test, data not shown), whereas treatment success rate during the follow-up and at the last exam were not significantly different whithin each SE group $(p=0.055,1.0,0.519$ for the hyperopia, emmetropia, and myopia group respectively, p-values by Chi-squared test, data not shown). There were 14 patients (5.19\%) in the hyperopia group, and 3 patients (4.41\%) in the myopia group who had once achieved treatment success, but failed to maintain it at the last exam. In a prospective follow-up study after treatment cessation in children with successfully treated amblyopia due to anisometropia, strabismus or both, the risk of amblyopia recurrence was reported to be $24 \%$ within the first year off treatment ${ }^{25}$. In other retrospective study also reported recurrence of amblyopia after a cessation of occlusion therapy was $27 \%$ within the first year off treatment ${ }^{26}$. Relatively lower recurrence rate of our result than previous studies may be due to given active treatment during the whole follow-up period in our subjects, such as re-occlusion therapy. It is also interesting that the emmetropia group had no recurrence at all, while the other two SE groups had some. Due to the small number of recurrent cases and possibility of visual acuity fluctuation during the follow-up, we defined our primary end-point as the treatment success rate during the follow-up.

There are some limitations in our study. Due to the retrospective study design, treatment method and duration were not able to controlled. Also, there was a limitation to evaluate the compliance of patching and wearing glasses. However, this study has its merit that a large scale study population recruited from a secondary referral eye hospital which would reflect the general population better than the tertiary referral hospitals. The goal of this study was to compare the treatment outcome depending on the SE type of amblyopic eye in anisometropia amblyopia in real world pediatric ophthalmology clinic. Also this is one of a few studies to evaluate the factors affecting amblyopia treatment success according to the refractive error type of amblyopic eye.

\section{Conclusions}

In conclusion, the amount of refractive error and astigmatism of the amblyopic eyes, and the difference in refractive errors between the two eyes were not significant factors affecting the amblyopia treatment success after adjusting other factors in all SE groups, in anisometropic amblyopia patients who visited a secondary referral eye hospital in South Korea. However, the treatment results and the factors affecting amblyopia treatment success were different according to the refractive error type of amblyopic eyes, therefore the SE type of the amblyopic eyes is the prognostic factor.

\section{Declarations}

Author contributions: The authors confirm contribution to the paper as follows: study conception and design: SHB, ESK, DHK; data collection: SHB, ESK, DHK; analysis and interpretation of results: SHB, DHK, DDC; draft manuscript preparation: DDC; All authors reviewed the results and approved the final version of the manuscript.References

\section{References}


1. Dirani M, Zhou B, Hornbeak D, et al. Prevalence and causes of decreased visual acuity in Singaporean Chinese preschoolers. British Journal of Ophthalmology. 2010;94:1561-1565.

2. Williams $\mathrm{C}$, Northstone $\mathrm{K}$, Howard M, et al. Prevalence and risk factors for common vision problems in children: data from the ALSPAC study. British Journal of Ophthalmology. 2008;92:959-964.

3. Multi-ethnic Pediatric Eye Disease Study G. Prevalence of amblyopia and strabismus in African American and Hispanic children ages 6 to 72 months the multi-ethnic pediatric eye disease study. Ophthalmology. 2008;115:1229-1236 e1221.

4. Friedman DS, Repka MX, Katz J, et al. Prevalence of amblyopia and strabismus in white and African American children aged 6 through 71 months the Baltimore Pediatric Eye Disease Study. Ophthalmology. 2009;116:2128-2134 e2121-2122.

5. Chekitaan, Karthikeyan B, Meenakshi S. The results of treatment of anisomyopic and anisohypermetropic amblyopia. Int Ophthalmol. 2009;29:231-237.

6. Kirandi EU, Akar S, Gokyigit B, et al. Risk factors for treatment failure and recurrence of anisometropic amblyopia. Int Ophthalmol. 2017;37:835-842.

7. Kutschke PJ, Scott WE, Keech RV. Anisometropic Amblyopia. Ophthalmology. 1991;98:258-263.

8. Rosenthal AR, von Noorden GK. Clinical Findings and Therapy in Unilateral High Myopia Associated with Amblyopia. American Journal of Ophthalmology. 1971;71:873-879.

9. Curtin BJ, Schlossman A. Unilateral high myopia in childhood: clinical characteristics and treatment. Am Orthopt J. 1976;26:6568.

10. Pang Y, Allison C, Frantz KA, et al. A prospective pilot study of treatment outcomes for amblyopia associated with myopic anisometropia. Arch Ophthalmol. 2012;130:579-584.

11. Pang Y, Frantz KA, Block S, et al. Effect of Amblyopia Treatment on Macular Thickness in Eyes With Myopic Anisometropic Amblyopia. Invest Ophthalmol Vis Sci. 2015;56:2677-2683.

12. Priestley BS, Hermann JS, Bloom M. Amblyopia Secondary To Unilateral High Myopia* Results of pleoptic therapy *From the Department of Pleoptics, New York Eye and Ear Infirmary. This study was supported by a Fight-for-Sight grant-in-aid of the National Council to Combat Blindness, Inc., New York. American Journal of Ophthalmology. 1963;56:926-932.

13. Soo-Yeon Cho M, Dae Hee Kim, MD, Ungsoo Samuel Kim, MD, PhD, Seung-Hee Baek, MD, PhD. Anisometropic Amblyopia: Distribution of Refractive Errors and Clinical Characteristics of Patients from an Eye Hospital. Ann Optom Contact Lens 2020:11-17.

14. Jampolsky A, Flom BC, Weymouth FW, Moses LE. Unequal corrected visual acuity as related to anisometropia. AMA Arch Ophthalmol. 1955;54:893-905.

15. Hussein MAW, Coats DK, Muthialu A, et al. Risk factors for treatment failure of anisometropic amblyopia. Journal of American Association for Pediatric Ophthalmology and Strabismus. 2004;8:429-434.

16. C J Cobb KR, A Cox, C J MacEwen. factors influencing visual outcome in anisometropic amblyopes. Br J Ophthalmol. 2002:12781281.

17. Afsari S, Rose KA, Gole GA, et al. Prevalence of anisometropia and its association with refractive error and amblyopia in preschool children. Br J Ophthalmol. 2013;97:1095-1099.

18. Hussein MA, Coats DK, Muthialu A, et al. Risk factors for treatment failure of anisometropic amblyopia. J AAPOS. 2004;8:429-434.

19. Hyun Chan Lee MMK. visual prognosis in children with astigmatic amblyopia. Journal of Korean Opthalmology society. $1996 ; 37$.

20. Kivlin JD, Flynn JT. Therapy of anisometropic amblyopia. J Pediatr Ophthalmol Strabismus. 1981;18:47-56.

21. Sullivan M. Results in the treatment of anisometropic amblyopia. Am Orthopt J. 1976;26:37-42. 
22. Hardman Lea SJ, Loades J, Rubinstein MP. The sensitive period for anisometropic amblyopia. Eye. 1989;3:783-790.

23. Helveston EM. Relationship between degree of anisometropia and depth of amblyopia. Am J Ophthalmol. 1966;62:757-759.

24. Chen PL, Chen JT, Tai MC, et al. Anisometropic amblyopia treated with spectacle correction alone: possible factors predicting success and time to start patching. Am J Ophthalmol. 2007;143:54-60.

25. Jonathan M. Holmes BM, B.Ch., Michele Melia, Sc.M., Yasmin S. Bradfield, M.D., Oscar A. Cruz, M.D., Brian Forbes, M.D., Ph.D., and Pediatric Eye Disease Investigator Group. Factors Associated with Recurrence of Amblyopia on Cessation of Patching. Ophthalmology:1427-1432.

26. Bhola R, Keech RV, Kutschke P, et al. Recurrence of amblyopia after occlusion therapy. Ophthalmology. 2006;113:2097-2100. 